\section{Eseigbe EE \\ Eseigbe $\mathbf{P}$ \\ Nuhu FT \\ Sheikh TL \\ Majebi MA \\ Kalu AO \\ Lasisi MD \\ Suleiman ZT \\ Sadiq EI \\ Banjo OO \\ Adebayo O}

DOI:http://dx.doi.org/10.4314/njp.v40i4,14

Accepted: 6th March 2013

Eseigbe EE ( $\quad$ )

Department of Paediatrics

Eseigbe $\mathrm{P}$,

Department of Family Medicine

Ahmadu Bello University Teaching

Hospital, Zaria Nigeria.

Email: eeeseigbe@yahoo.com

Nuhu FT, Sheikh TL, Majebi MA

Kalu AO, Lasisi MD, Suleiman ZT

Sadiq EI, Banjo OO, Adebayo O

Federal Neuro -Psychiatric Hospital,

Kaduna, Nigeria.

\title{
Impact of childhood mental health disorders on the family: A Case report
}

\begin{abstract}
Background: Care of the children with mental health disorders is fraught with challenges particularly in developing countries and, where the family is the major source of care. Consequently assessing the impact of these disorders on the family is relevant to providing these children with optimal care.

Objective: To assess the impact of childhood mental health disorders on family function and parental burden.

Method: A monogamous family that had 3 children diagnosed as having childhood onset schizophrenia using the International Classification of Disease version 10(ICD 10) Classification was studied. Family function was assessed using the Family APGAR Score and the Zarit Burden Interview (ZBI) Score used in assessing parental burden.

Results: The Family APGAR Scores were low (highly
\end{abstract}

dysfunctional family) and the ZBI Scores high (highly burdened) in the family. Areas of serious dysfunction in the family were in adaptation, partnership and growth. In the ZBI Scores feelings about quality and cost of care offered, stress and other negative attributes associated with providing care, inability to meet other parental obligations and uncertainty about the future, were the major contributors to the highly burdensome outcome.

Conclusion: The study highlights significant family burden and dysfunction in a family who had three children with schizophrenia. It underscored the need for provision of more comprehensive health and social support services to children with mental health disorders and their families.

Key Words: Childhood, Schizophrenia, Parent, Burden, Family function

\section{Introduction}

Globally an estimated $20 \%$ of children and adolescents suffer from mental disorders. ${ }^{1}$ Prevalence rates of 15 $20 \%$ for childhood mental disorders have been reported from specific child populations in Nigeria. ${ }^{2}$ Parental psychopathology, in addition to low socio economic status and exposure to physical violence, has been reported to be strongly associated with childhood mental health disorders. ${ }^{3,4}$ In spite of the magnitude of the problem childhood mental health services are either not available or not accessible in low and middle income countries. ${ }^{1}$ In response to this the World Health Organization developed the Mental Health Gap Action Programme (mhGAP) for countries especially with low and middle incomes for scaling up services for mental, neurological and substance use disorders. ${ }^{1}$ Notwithstanding, the family still plays an important role in the provision of care in countries where mental health services are deficient.

Assessing how the family and its members cope with 
these disorders is crucial to provision of optimal care in these countries. The Family APGAR Score and the Zarit Burden Interview (ZBI) Score are two instruments that, have been validated and found reliable, are useful in the assessment of family function and caregiver burden respectively. ${ }^{5,6}$

This is the first case, out of the 600 cases seen in the first year of the newly inaugurated child and adolescent mental health (CAMH) unit of the Federal Neuro Psychiatric Hospital Kaduna (FNPHK), of three siblings presenting with the same mental health disorder in a non consanguineous monogamous setting.

The aim of this study was to assess family function and parental burden in a family having three children with a mental health disorder.

\section{Case report}

This case report is about a monogamous family with four female children and three of the children, aged 12 , 15 and 17 years, diagnosed as having schizophrenia using the International Classification of Diseases version

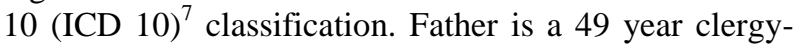
man while mother a 44 year old petty trader with a history of schizophrenia and receiving treatment in the same hospital. There was no history of the disorder in the extended family. The parents are the sole providers of care for their children with, occasional financial support from well wishers. They have neither received nor are they aware of any form of governmental or institutional support.

Family function and parental burden were assessed using the Family APGAR and ZBI Scores respectively. The Family APGAR Score uses the family's member perception of satisfaction to assess 5 dimensions of family functioning namely Adaptability, Partnership, Growth, Affection, and Resolve. ${ }^{5}$ Each parameter is assessed on a 3-point scale ranging from 0(hardly ever) to 2(almost always). The final grading is thus: 0-3 (Highly dysfunctional family), 4-6(Moderately dysfunctional family) and 7-10(Highly functional family). The Family APGAR Score has been found valid and reliable. The mean of each parental Family APGAR Score for the children was used as an indicator score for assessing family dysfunction. The ZBI Score, whose test-retest reliability and face validity has been established in Nigeria, is a 22-item self-report inventory that examines burden associated with functional/behavioural impairments and the home care situation. ${ }^{6}$ Each question is scored on a 5 point-scale ranging from never(0) to nearly always present(4). Total scores range from 0 (lowest burden) to 88 (highest burden). The mean of each parental ZBI Score for the children was used as the indicator score for assessing burden in this study.

The parental Family APGAR Scores and their mean scores were the same for all children. Father's and mother's score for each child was 3(highly dysfunctional family). The parameters associated with the lowest possible score (0) in the family were in adaptability, partnership and growth while scores of 1 and 2 were recorded in affection and resolve respectively.

Concerning the ZBI Scores the mother had a higher mean score $(80)$, though not significant $(P=0.12)$, than the father's $(79.7 \pm 0.6)$. The areas associated with high burdensome scores(3-4) by the parents were with regards to; quality and cost of care offered, stress and other negative attributes such as embarrassment associated with providing care, inability to meet other parental obligations and uncertainty about the future.

Family therapy, in addition to management of schizophrenia, was instituted in the family.

\section{Discussion}

The study showed high family dysfunction and parental burden in a family that had three children with childhood onset schizophrenia. There has been a previous report on 11 cases of families having 5 to 11 members affected by the disorder but this was in an ethnically isolated community with a history of endogamy. ${ }^{7}$ The history of mental health disorder in the family supports the reported strong association between parent psychopathology and childhood mental health disorders. However genetic studies would be required to provide further information. High caregiver burden, using the ZBI Score, have been reported in the provision of care for children and adolescents with mental health disorders. ${ }^{8}$ The number of children with the disorder in the family, maternal history of the disorder, the family's socio economic status and insufficient family support would have contributed to the degree of burden felt. Furthermore the history of maternal schizophrenia coupled with a woman's pivotal role in providing home care in the African setting could have contributed to the higher mean ZBI Score in the mother. ${ }^{9}$ Family dysfunction, using Family APGAR Score, have been reported in families caring for members with a chronic debilitating illness. ${ }^{10}$ It would appear that a high level of parental burden correlates positively with family dysfunction but the population size of this study makes the observation inconclusive. However, it provides a basis for further research into this association in our environment.

The impact of having highly burdened parents or a dysfunctional family is far-reaching and adverse. The family could suffer communal isolation as a result of stigmatization or a breakdown as a result of a member or members abdicating their responsibilities. Coping parents could experience; less productivity, inability to meet other obligations and potentially incapacitating stress. The children could end up receiving suboptimal care, subjected to stigmatization as well, discriminated against, abused or neglected, suffer deterioration in the clinical state and even death. ${ }^{7,11}$

Relieving parental burden and supporting affected families limit development of these consequences. Identification of susceptible families and their burdens, as has 
been noted in this study, improving level of awareness, provision of supportive social and specialist health services, and active participation in relevant global initiatives such as the Mental Health Gap Action Programme (mhGAP) are some ameliorating measures.
Conflict of interest: None

Funding: None

\section{References}

1. World Health Organization (2008). Mental Health Gap Action Programme (mhGAP): Scaling up care for mental, neurological and substance use disorders. whqlibdoc.who.int/publicaions/ 2008/978924596206_eng.pdf Accessed 30/10/12

2. Gureje O, Omigbodun OO, Gater R, Acha RA, Ikuesan BA, Morris J. Psychiatric disorders in a pediatric primary care clinic. $B r J$ Psych 1994; 165:527-30

3. McLaughlin KA, Gadermann AM, Hwang I, Sampson NA, AlHamzawi A, Andrade LH et al. Parent psychopathology and offspring mental disorders: results from the WHO World Mental Health Surveys. Br J Psych 2012; 200(4):290-9

4. Fatori D, Bordin IA, Curto BM, de Paula CS. Influence of psychosocial risk factors on the trajectory of mental health problems from childhood to adolescence: a longitudinal study. BMC Psychiatry 2013, $13: 31-31$
5. Smilkstein G. The Family APGAR: A proposal for family function test and its use by physicians. J Fam Pract 1978; 6(6):1231-39

6. Zarit SH, Reever KE, BachPeterson J. Relatives of the impaired elderly: correlates of feeling of burden. Gerontologist 1980; 20:649-55

7. Lewis S, Escalona PR, Keith SJ. Phenomenology of schizophrenia. In Sadock BJ, Sadock VA, Ruiz P, eds. Kaplan's and Sadock's comprehensive textbook of psychiatry, Philadelphia: Lippincott, Williams\&Wilkins, 2009:pp1433-51

8. Dada MU, Okewole NO, Ogun OC, Bello-Mojeed MA. Factors associated with caregiver burden in a child and adolescent psychiatric facility in Lagos, Nigeria: a descriptive cross sectional study. BMC Pediatr 2011; 11: 110 -
9. Eseigbe EE, Anyiam JO, Wammanda RD. Care of the Child with Special Health Care Needs: A Report on 2 Nigerian Children with Muscular Dystrophy. Ann Niger Med 2006; 2(2): 29-31

10. Panganiban-Corales AT, Medina MF. Family resources study part 1 : family resources, family function and caregiver strain in childhood cancer. Asia Pac Fam Med 2011; 10(1):10-14

10. Arboleda-Florez J. Stigma and Discrimination: an overview. World Psychiatry 2005;(4:S1):810 